\title{
Breve Referencia a la Especial Naturaleza de la Obligación Incorporada en el Pagaré
}

\section{Héctor Manuel Murguía Murguía}

SUMARIO: I.- Introducción. II.- Referencia histórica del pagaré. III.- Especial naturaleza de la obligación incorporada en el pagaré dentro del contexto de las fuentes generales y específicas de obligaciones. IV.- Síntesis o conclusión.

Resumen: Por ser el pagaré el título de crédito que más aplicaciones prácticas ha tenido y sigue teniendo y con el objetivo de entender la naturaleza especial de la obligación en él consignada o incorporada, necesario es analizar sus características más relevantes, a saber: constitutiva, que como documento goza, toda vez que en ese pedazo de papel se genera la relación jurídico cambiaria; formal, para que produzca sus efectos deben incorporarse al pedazo de papel los requisitos que la ley exige; legitimadora, faculta tanto al pasivo como al activo a realizar válidamente ciertos actos; a la orden, generalmente endosable en propiedad; ejecutivo, desde el emplazamiento se embargan bienes al demandado para garantizar el capital y accesorios y por último, su carácter dispositivo, lo que implica el imperativo categórico de su exhibición material para estar en aptitud de ejercer el derecho de cobro de una cantidad determinada, siempre de dinero, literalmente plasmada en el mismo y contra todos sus signatarios.

Palabras Clave: Pagaré, obligaciones incorporadas

Abstract : As the promissory note is the title of credit that more practical applications have had and still have and with the aim of understanding the special nature of the contained obligation or incorporated, it is necessary to analyze its most relevant characteristics, namely: Constitutive, which as Document enjoys, since in that piece of paper the legal exchange relationship is generated; Formal, in order to produce its effects must incorporate to the piece of paper the requirements that the law requires; Legitimating, authorizes both the liability and the asset to validly perform certain acts; To the order, generally endorsable in property; Executive, the defendant is seized of assets to guarantee the capital and

\footnotetext{
${ }^{1}$ Héctor Manuel Murguía Murguía, Docente de la Universidad de Sonora, integrante de la Academia de Derecho Mercantil, Candidato a Doctor por el Centro de Estudios Superiores en Ciencias Jurídicas y Criminológicas Unidad de Enlace Sonora.
} 
accessories and finally, its device character, which implies the categorical imperative of its material exhibition to be able to exercise the right to collect a certain amount, always Of money, literally embodied in it and against all its signatories.

Key Words: Promissory note,contained obligation

\section{Introducción}

Para obtener el modesto objetivo de este trabajo, es indispensable analizar someramente las características del pagaré, aunque originalmente la letra de cambio fue considerada como el más importante de los títulos de crédito, entendiéndose que prácticamente la legislación cambiaria giró en torno a ella y no obstante que el pagaré la precede, fue desplazado por aquella en virtud a su estructuración y especial naturaleza ejecutiva que permitió la iniciación y conclusión de varios negocios a la vez, razones por las cuales el pagaré cayó en desuso ya que en sus inicios no tenía el carácter ejecutivo. Años más tarde sucedió el mismo fenómeno pero a la inversa, el pagaré desplazó a la letra de cambio y en la actualidad es el título más utilizado como instrumento de crédito con variadísimas aplicaciones prácticas y generalmente, difiere el pago de servicios y bienes adquiridos por el suscriptor, salvo el caso de vencimiento a la "vista", y para este objetivo, es necesario recurrir a la definición legal de título de crédito.

"Son títulos de crédito, los documentos necesarios para ejercitar el derecho literal que en ellos se consigna."

Por lo que respecta al concepto autonomía, tenemos que el jurisconsulto Cesar Vivante (italiano) en el año de 1895, en su monografía sobre los títulos-valores, fue el primero quizás en darle una definición a este concepto: "Es todo documento necesario para ejercer el derecho literal y autónomo que de él resulta". ${ }^{3}$

\footnotetext{
${ }^{2}$ Ley General de Títulos y Operaciones de Crédito, en vigor a partir del día 15 de Septiembre de 1932

${ }^{3}$ Vivante, Cesar. http://es.slideshare.net/videoconferencias/de-los-ttulos-valor15685870
} 
L. Carlos Felipe Dávalos Mejía agrega a esta definición legal otras características tales como la circulación, la formalidad y de carácter ejecutivo (artículo $6^{\circ}, 21$ y 25 ; 14; 167 respectivamente de la Ley General de títulos y Operaciones de Crédito) y nos proporciona una definición más amplia:

"Son títulos de crédito los documentos ejecutivos que se emiten para circular, que cumplen con las formalidades de ley y que, para aquel que se legitime como su propietario, son indispensables para ejercitar el derecho literal y autónomo que en ellos se consigna"4

Raúl Cervantes Ahumada, haciendo una referencia a la clasificación de los actos de comercio sostiene: "Cabe advertir que los títulos de crédito son cosas absolutamente mercantiles, por lo que su mercantilidad no se altera porque no sean comerciantes quienes los suscriban o los posean."

Procede hacer una somera explicación de las características integradas a la definición que antecede y así tenemos que:

a) Incorporación. Es la característica fundamental y la doctrina ha preferido este concepto por ser más explícito e ilustrativo, ya que la consignación, por ser polisémica, puede inducir a error e incorrecta valoración y así tenemos que el fenómeno cambiario de la incorporación, asume por necesidad la existencia de dos elementos: un pedazo de papel al cual se le incorpora el derecho de cobro generando un relación de necesidad, de naturaleza indisoluble que se obtiene precisamente al plasmar en ese pedazo de papel todos y cada uno de los requisitos del pagaré exigidos en el artículo 170 de la Ley General de Títulos y Operaciones de Crédito y que se clasifican en esenciales y no esenciales: ${ }^{5}$

\footnotetext{
${ }^{4}$ Dávalos Mejía, L. Carlos Felipe,Títulos y Operaciones de Crédito, Tercera Edición, Ed. OXFORD. pp. 64

${ }^{5}$ Tena, Felipe de J., Derecho Mercantil Mexicano, Vigesimosegunda Edición, Ed. Porrua
} 
Esenciales.- Por su propia naturaleza deben necesariamente estar plasmados en el documento, toda vez que la ley no los presume y la falta de uno acarrea la inexistencia del título de crédito, gozando de esta característica todos los requisitos exigidos por el numeral antes señalado, a excepción de la época y lugar de pago; faltando un requisito esencial tendremos un simple documento confesorio mas no un auténtico título de crédito, pagaré y algunos autores, por la relevancia que adquiere el papel, sin el cual no habría relación cambiaria, a la ley que lo estructura o reglamenta, la denominan derecho documental o cartular. ${ }^{6}$

No esenciales.- Tienen este carácter porque la ley sí los presume y por lo tanto, se pueden omitir sin sancionar al pagaré con nulidad que como ya se dijo, son la época y lugar de pago y en el supuesto de que no se hayan incorporado, se entenderá pagadero "a la vista" y en el domicilio del suscriptor, respectivamente, al tenor del artículo 171 en relación con el 79 de la referida ley. ${ }^{7}$

b) Literalidad. Parafraseando a Felipe de J. Tena, la literalidad resulta ser la objetivación de la realidad jurídica plasmada en el papel, por lo que es obvia su naturaleza imprescindible para llevar acabo el fenómeno de la incorporación, ya que sin palabras, el documento jamás nacería a la vida jurídica, cambiaria, porque el pagaré es intrínsecamente formal ya que la relación jurídica nace en el mismo y que por ningún motivo puede ser verbal, como sí acontece en ciertos contratos que son consensuales en oposición a formales, entre otros, el arrendamiento civil. Se puede sostener que la literalidad produce plenamente sus efectos siempre y cuando no viole norma legal alguna, generando la relación cambiaria, precisamente en el papel en el cual se plasmaron palabras acordes a la naturaleza del pagaré, surgiendo un sujeto pasivo, deudor, entiéndase suscriptor, por cierto no fungible, es decir, invariable, al cual le genera la

\footnotetext{
${ }^{6}$ Tena, Felipe de J., op.cit.

${ }^{7}$ lbid
} 
convicción del alcance y extensión de su obligación, el lugar y fecha en que contrajo, así como la época y el lugar en que debe cumplirla. ${ }^{8}$

También la literalidad genera o produce a favor del sujeto activo, acreedor cambiario, la convicción de la extensión de su derecho y demás circunstancias, con la salvedad de que este elemento personal es fungible, es decir, variante, consecuencia de la naturaleza del pagaré que nace para circular, en el entendido de que el ultimo endosatario o acreedor para poderlo cobrar, necesita exhibirlo, (carácter dispositivo) siempre y cuando esté legitimado, según lo establecen, entre otros, los artículos 17 y 38 segundo párrafo de la ley en consulta. ${ }^{9}$

La literalidad del pagaré, la promesa de pagar una suma determinada de dinero que externa el suscriptor, no debe entenderse hecha exclusivamente a favor del tomador beneficiario original, sino que la emite erga omnes, en virtud de que este título de crédito nace para circular por cualquier medio legal, cesión, donación, o bien, por el único de naturaleza cambiaria, el endoso en propiedad y el ultimo endosatario, se individualiza al presentar el pagaré para su cobro como legítimo tenedor.

En este orden de ideas, tenemos que en la relación jurídica cambiaria el único sujeto constante es el suscriptor (y su avalista) y por el contrario, fungible $O$ variante el acreedor cambiario, ya que la fórmula "a la orden" referida en el artículo 25 de la citada ley, contenida en el texto del pagaré, históricamente debe entenderse que el valor literal deberá ser pagado a favor de la persona que indique el tenedor beneficiario, es decir, a quien se lo endose, según lo establecen la doctrina, la jurisprudencia y la ley, implicando que el suscriptor, obligado a pagar el título de crédito, no sepa al momento de la suscripción del mismo, a quién ha de hacerle el pago, circunstancia que por cierto resulta irrelevante ya que en última instancia, para hacer un pago perfecto, es decir, liberatorio de su obligación, deberá observar las prevenciones contenidas en el artículo 39 de la ley en cita,

\footnotetext{
${ }^{8}$ ibidem

${ }^{9}$ Cervantes Ahumada, Raúl,Títulos y Operaciones de Crédito,Ed. Porrúa,México,
} 
numeral que contiene regla especial a saber: identidad de la persona que presenta el título para su pago como último tenedor, es decir, que su nombre coincida con el que aparece como último endosatario y además, la continuidad de los endosos, no siendo obligación a cargo del que paga, cerciorarse de la autenticidad de los mismos, ni mucho menos, exigir su comprobación.

Por último, la literalidad también tiene como función perfeccionar el contenido del pagaré al limitar la voluntad del que lo llena, prohibiéndole incorporar palabras que degraden su naturaleza y que de no observarse la formalidad cambiaria, devienen, a saber, tres clases de sanciones derivadas de la Ley General de Títulos y Operaciones de Crédito:

1.-Se tendrá por no escrito, (artículos $31,78,87,88,141,178,183$ y 197).

2.- Será nulo, (artículo 31).

3.- No surtirá efectos, (artículos 14, 20, 38, 228 b) y 229).

c) Formalidad. El artículo 14 exige la observancia de la formalidad cambiaria en los documentos y en los actos que en ellos se plasman y que de no cumplirse, acarrea su inexistencia al omitirse en el pagaré, cualquiera de los requisitos esenciales contenidos en el diverso numeral 170 y que cumplida, producirá plenamente sus efectos, por lo que en esta hipótesis, no surgen hechos que conformen excepciones materiales en contra del mismo, es decir, son actos jurídicos perfectos y consecuentemente, productores de sus efectos consustanciales, plenamente. ${ }^{10}$

Si bien es cierto que la omisión de uno de los requisitos esenciales produce la inexistencia del título de crédito, también resulta muy cierto que esta sanción no afecta al negocio jurídico subyacente, generalmente el contrato, si éste cumple con todos y cada uno de los requisitos de validez exigidos por la ley de la materia.

${ }^{10}$ Ley General de Títulos y Operaciones de Crédito, en vigor a partir del día 15 de Septiembre de 1932 
En cambio, la inexistencia o invalidez del contrato subyacente, afecta al título de crédito con la misma sanción, siempre y cuando éste no se haya endosado en propiedad.

Para tener una idea más clara de la naturaleza especial de la obligación incorporada en el pagaré, que siempre es de dar, pagar una suma determinada de dinero, es necesario un análisis más a fondo del diverso requisito contenido en la fracción VI del referido artículo 170, la firma del suscriptor o de la persona que firme a su ruego o en su nombre, toda vez que la autógrafa, es considerada como la fuente de la obligación cambiaria, por cierto de naturaleza muy especial y que abordaremos con mayor detalle en el siguiente capítulo.

d) Legitimación.La legitimación es una consecuencia del fenómeno cambiario de la incorporación y en términos generales, implica la facultad o potestad de realizar válidamente una conducta y al efecto, procede analizar la relación jurídico sustantiva que nace en el pagaré y de la cual surge un sujeto activo o acreedor, que es precisamente su tenedor beneficiario y un sujeto pasivo denominado deudor y que se obliga este último a realizar una conducta de dar al hacer la promesa incondicional de pagar una suma determinada de dinero, en una época y lugar también determinados; promesa que se ubica dentro de las fuentes generales de obligaciones, acto jurídico, concretamente la declaración unilateral de voluntad de naturaleza atípica ya que no puede ser revocada y emitida no precisamente a favor del tomador beneficiario original del título de crédito, sino a la orden de éste, como consecuencia de la naturaleza circulatoria del pagaré y que como documento, papel, es constitutivo, lo que implica que sólo en el pedazo de papel que lo contiene se configura o nace la relación jurídica sustantiva y en la hipótesis de que no se haya endosado en propiedad, por su propietario original, la ley determina categóricamente que es propietario del título ya que fue expedido a su nombre (nominativo) 
y no lo ha endosado en propiedad, consecuentemente, legitimado para cobrarlo al tenor del artículo 38 primera parte, en relación con el 23 de la Ley General de Títulos y Operaciones de crédito. ${ }^{11}$

En la hipótesis de que se haya endosado en propiedad, también resulta aplicable el mismo numeral 38, pero en su segundo párrafo, el cual ya no es categórico al afirmar que sea propietario, sino por el contrario, lo considera propietario formal del documento, siendo más relevante que se encuentre legitimado para su cobro por el endoso o cadena de endosos, a que realmente sea propietario.

En ambos supuestos, porque el pagaré como documento es dispositivo, su tenedor beneficiario, acreedor, está obligado a exhibirlo en su original al exigir el pago y si le es cubierto en su totalidad, también está obligado a devolverlo, según lo mandatan los artículos 17, 126 y 127 de la referida codificación y así estaremos en la hipótesis de un pago perfecto en cuanto a tiempo, modo, lugar y sustancia, y consecuentemente liberatorio de la obligación, quien al recuperar el pagaré, éste es la prueba fehaciente de su cumplimiento y en la hipótesis de que el acreedor no haga su devolución y para no incurrir en mora, se debe hacer la consignación de su valor literal ante el juzgado mercantil correspondiente mediante certificado de depósito al tenor del artículo 132 de la Ley en comento.

e) Autonomía. Nuestra legislación, doctrina y jurisprudencia, no conceptúan al pagaré en sí mismo como autónomo en la hipótesis de que no haya sido endosado en propiedad, es decir, que su propietario original to conserve para que a su vencimiento exija su pago, lo que implica que está vinculada a la causa subyacente, fundamental por la cual se suscribió, generalmente un contrato y tan es así, que todo lo que afecte al negocio jurídico del cual emana, afectará directamente al derecho incorporado al pagaré. $^{12}$

\footnotetext{
11 ibidem

12 Tena, Felipe de J ., ibid
} 
Efectivamente, el artículo 14 segundo párrafo de la Ley General de Titulo y Operaciones de Crédito así lo determina, corroborado por la fracción XI del artículo $8^{\circ}$ de la misma, que faculta al demandado a oponer en contra de la acción cambiaria las excepciones personales que tenga contra el actor y precisamente éstas, las personales, por regla general tienen su fuente en la causa subyacente, el contrato y qué si éste fuese declarado inexistente o nulo, también afectaría con las mismas sanciones al pagaré.

Debemos entender, en la hipótesis de que el pagaré no ha sido endosado en propiedad, que la autonomía no se manifiesta plenamente, pero se acepta que este título de crédito, una vez incorporados al papel todos los requisitos contenidos en el artículo 170, los esenciales, nace a la vida cambiaria y por sí mismo y sin necesidad de otro documento, puede demandarse judicialmente su pago ya que se considera como documento procesalmente eficaz, sin necesidad de acompañarlo de otro, es decir, tiene cierta autonomía.

Siendo en la diversa hipótesis, que el pagaré haya sido endosado en propiedad, cuando surgen los fenómenos cambiarios de abstracción y autonomía y se manifiesta en plenitud el nuevo derecho de cobro, cuya fuente es el acto jurídico, endoso en propiedad y para entender cabalmente los referidos fenómenos, se hace transcripción de la siguiente jurisprudencia:

Época: Novena Época

Registro: 193208

Instancia: Primera Sala

Tipo de Tesis: Jurisprudencia

Fuente: Semanario Judicial de la Federación y su Gaceta

Tomo X, Octubre de 1999

Materia/s): Civil

Tesis: $1^{\mathrm{a}} . / \mathrm{J} .51 / 99$

Pagina:284

TÍTULOS DE CRÉDITO. DIFERENCIAS ENTRE LA AUTONOMÍA $\quad Y \quad$ LA

ABSTRACCIÓN. La desvinculación de un título de crédito de la causa que le dio 
origen, no se traduce en un problema de autonomía, sino de abstracción. Mientras que aquélla importa la existencia de un derecho originario, es decir, desvinculado de la posición jurídica de sus anteriores portadores, la segunda desvincula al documento de la relación causal. Por virtud de la autonomía el poseedor de buena fe es inmune a las excepciones personales oponibles a los anteriores poseedores. En razón de la abstracción, en cambio, no pueden ser opuestas al tercer portador las excepciones derivadas de la relación causal. De lo expuesto se sigue que tratándose de pagarés quirografarios que no han circulado, la autonomía no comienza a funcionar; y la abstracción se atenúa, en razón de que el demandado puede oponer al actor las excepciones que tuviera contra éste, en términos del artículo 80., fracción XI, de la Ley General de Títulos y Operaciones de Crédito, lo que no impide que ese título baste, sin necesidad de otro documento, para intentar la acción cambiaria respectiva.

Contradicción de tesis 24/97. Entre las sustentadas por el Noveno Tribunal Colegiado en Materia Civil del Primer Circuito y Primero y Segundo Tribunales Colegiados, ambos del Décimo Cuarto Circuito y Séptimo Tribunal Colegiado en Materia Civil del Primer Circuito. 22 de septiembre de 1999. Unanimidad de cuatro votos. Ausente: Humberto Román Palacios. Ponente: Olga Sánchez Cordero de García Villegas. Secretario: Marco Antonio Rodríguez Barajas.

Tesis de jurisprudencia 51/99. Aprobada por la Primera Sala de esta Suprema Corte de Justicia de la Nación, en sesión de veintidós de septiembre de mil novecientos noventa y nueve, por unanimidad de cuatro votos de los señores Ministros: presidente en funciones Juventino V. Castro y Castro, José de Jesús Gudiño Pelayo, Juan N. Silva Meza y Olga Sánchez Cordero de García Villegas. Ausente: Ministro Humberto Román Palacios.

f) Ejecutividad.- Ya se ha manifestado que el pagaré como documento es dispositivo, título privilegiado, prueba preconstituída y que por su naturaleza constitutiva se hace indispensable su exhibición con la 
demanda como fundamento de la acción cambiaria, según lo mandata el artículo 1392 del Código de Comercio y una vez radicada, el juez ordena requerir de pago a la parte demandada, suscriptor, avalista y endosantes en propiedad y si no lo hacen en el momento de la diligencia, se les embargan bienes de su propiedad suficientes a garantizar las prestaciones reclamadas y acto continuo, se les emplaza para que dentro del plazo de 8 días adopten cualquiera de las siguientes conductas procesales:

- Pago de la cantidad reclamada y costas,

- Oponer las acepciones que tuviere y únicamente las contenidas en el artículo $8^{\circ}$ de la Ley General de Títulos y Operaciones de Crédito,

Las dos anteriores, se derivan del artículo 1396 del Código de Comercio.

- Allanarse a la demanda en los términos del artículo 1405 del mismo Código de Comercio y en esta hipótesis, existe laguna ya que este numeral no indica sus consecuencias, por lo que al tenor del artículo 1054 de este ordenamiento legal, resulta supletoriamente aplicable el Código Federal de Procedimientos Civiles y que en su artículo 376 fracción II, determina que en caso de allanamiento no habrá condenación en costas, en íntima relación con la fracción I del diverso numeral 373 , segunda parte, que establece que el proceso caduca por causa que haga desaparecer substancialmente la materia del litigio, resultando obvio que el allanamiento, uno de sus efectos precisamente es desaparecer la controversia o litigio, corroborado lo anterior con el contenido del diverso numeral 345 que determina, que sin más trámite, se pronunciara la sentencia.

Es aquí precisamente donde se advierte la naturaleza ejecutiva del pagaré, implicando que el actor va a continuar el juicio ya garantizadas previamente sus prestaciones, desde el emplazamiento, ejecutividad de la cual no gozan muchos documentos porque son simplemente demostrativos y éstos, cuando son sustento de una acción, será hasta la ejecución forzosa de sentencia cuando se procede al 
correspondiente embargo, según lo indica el artículo 1391 fracción I del Código de Comercio al determinar que traen aparejada ejecución, la sentencia ejecutoriada pasada en autoridad de cosa juzgada y la arbitral.

\section{Referencia Histórica del Pagaré.}

"En opinión de Roblot, en virtud de que el pagaré contenía la inserción de una obligación directa, en rem (algo insólito en aquella época), necesariamente propició que durante los primero años -tal vez cientos- de su origen, fuera utilizado no por los comerciantes sino, de manera fundamental por los bancos del medievo, aún antes de que siquiera utilizarán la letra de cambio; al extremo de que se motivaron los importantes consecuencias: (i) por una parte, durante los primeros 200 años en uso, el pagaré existió en Europa continental del Renacimiento más como un pagaré bancario (billet de banque) que como un pagaré mercantil propiamente dicho (billet orde); y por otra, (ii) el documento y su uso bancario se conformaron en el antecedente real e incuestionable del papel moneda, a grado de que su fórmula cambiaría, que es adoptada en los derechos de todos los países, en la actualidad es la misma que se inserta en todos los papeles moneda (billetes), a saber "la promesa incondicional de pagar una suma determinada de dinero..." ${ }^{13}$

"Sin embargo, la razón de que en aquellas épocas el pagaré haya sido menos utilizado que la letra de cambio no obedece al uso casi monopólico que en los bancos hicieron de él, sino a otros motivos de orden sociológico. En efecto, como contenía el reconocimiento de una deuda, el pagaré era el título que más se acomodaba a la realización de la usura, actividad que no sólo era prohibida sino que era rebotada por la conciencia de la mayoría de los comerciantes que negociaban con otra cosa que no fuera dinero; luego, al identificarse con la usura, de preferencia no se utilizaba el pagaré. En razón de que desde su nacimiento los pagarés fueron a la orden, es decir, eran transmisibles por endoso, y por no estar

${ }^{13}$ Dávalos Mejía, L. Carlos, Títulos y Contratos de Crédito, Quiebras, Segunda Edición; Ed. Harla,México, 
sustentado en un contrato, como la letra, el emisor -en palabra de Roblot- sentía repugnancia por una obligación contraída con un desconocido, cuyo conocimiento no tendría lugar sino hasta la fecha del pago, pues no sabía a quién le iba a pagar: pudiera ser un competidor enemigo, un burócrata e, incluso un usurero $u$ otra persona no grata a los ojos del comerciante. Estas y otras razones similares fueron tan importantes y persistentes que, en efecto, la regulación legal del pagaré se hizo de manera tímida y como una tarea molesta que solo se deseaba terminar, al grado que el Código Bonaparte de 1807 apenas señaló algunos principios generales en sus arts. 187 y 188, la Ley Alemana de 1848, de manera análoga, en sus arts. 75 a 78 , aún que ésta perfecciono el tratamiento del pagaré en los arts. 21 y siguientes de su anexo II."14

"De igual rechazo fue objeto el pagaré en el Reino Unido y los países nórdicos, pero no por las mismas razones que en la Europa central, de claro convencionalismo social, sino por razones de orden técnico legal. En efecto, los comerciantes y las corte buscaban rendir homenaje a la perfección cambiaria de la letra, a la cual defendían a ultranza después de varios siglos de uso eficiente; y como una manera de hacerlo rechazaban en los notes, la carencia de seguridad jurídica que significaba el poder ser emitidos al portado, y preferían condicionar su emisión a que no fueran negociables y, de ser posible, de acuerdo con cada negocio, a que estuvieran ligados a un contrato mercantil cualquiera. Sin embargo, la enorme gama de posibilidades que permitía el note (pagaré) en materia bancaria, y al ser Inglaterra, en aquella época, el origen de prácticamente la totalidad de las instituciones bancarias, eso propició que finalmente fuera reglamentado de manera amplia, en la sección 83 de la Bill of Exchabges Act de 1882, incluso como un título susceptible de ser emitido a la orden o al portador, con lo que ese país se convirtió una vez más, en el pionero de una estructura legal..."15

\footnotetext{
${ }_{14}^{14}$ Dávalos Mejía, L. Carlos, op.cit.

${ }^{15}$ Ibid
} 
"Como sea, el pagaré es en la actualidad, el título de crédito más difundido entre los comerciantes y las empresas (privadas y paraestatales) que opere de acuerdo con considerados de orden puramente mercantil, y que, por cualquier motivo, se deban dinero. Su tipología comercial ha permanecido inalterada desde su creación, a saber, es el respaldo personal del pago de un préstamo, pero con la diferencia de que, en la actualidad y desde hace ya varios siglos, el préstamo con interés -el crédito- no está prohibido, por lo que sigue siendo, de manera frecuente utilizando por las instituciones de préstamo pe excelencia: los bancos. Entonces el pagaré es, lisa y simple e te, el título en el cual una persona contraer, in rem, la obligación de pagar de determinada cantidad de dinero a la orden de otra, en una fecha cierta..."16

\section{III.- Especial Naturaleza de la Obligación Incorporada en el Pagaré Dentro del Contexto de las Fuentes Generales y Específicas de Obligaciones}

Como las fuentes generales y específicas de obligaciones están debidamente reglamentadas en el derecho civil, habremos de recurrir a él para obtener su definición legal y a diversos autores para la concepción doctrinal del concepto "obligación":

"Artículo 1906.- La obligación es una relación jurídica que impone a una persona el deber de prestar a otra un hecho o abstención, o el de dar una cosa."17

Al surgir un derecho subjetivo, también surge la obligación a cargo de una persona, entendida, la "obligación", según el autor Rafael Rojina Villegas como "un vínculo jurídico por virtud del cual una persona denominada deudor, se encuentra constreñida jurídicamente a ejecutar algo en favor de otra persona, llamada acreedor."

\footnotetext{
${ }^{16}$ Ibidem

${ }^{17}$ Código Civil para el Estado de Sonora, vigente a partir del 8 de julio de 1949.
} 
Al respecto, el autor Manuel Bejarano Sánchez define a la "obligación", como: "la necesidad jurídica que tiene la persona llamada deudor, de conceder otra llamada acreedor una prestación de dar, de hacer o de no hacer" ${ }^{18}$

Como ya se indicó en los capítulos anteriores, la firma, requisito esencial en el pagaré, es considerada por la doctrina, ley y la jurisprudencia como la causa o fuente de la obligación cambiaria siempre de dar, paga una suma determinada de dinero y que deber ser autógrafa y al respecto, Felipe de J. Tena nos manifiesta: “ La firma autógrafa del suscritor: he aquí (con tal cual reserva de que hablaremos después) el único requisito que, de acuerdo con la letra y espíritu del art. $8^{\circ}$, debe tenerse como necesario y suficiente para que el suscritor del título esté obligado a pagarlo. De nada del serviría probar que lo firmó por error, dolo, violencia y simulación. El poseedor de buena fe es inmune a tales excepciones, por ignorar el hecho en que se fundan." ${ }^{19}$

El suscriptor, contrae así una obligación personal, produciéndose el mismo efecto de obligatoriedad en el supuesto de la firma a ruego contemplado en el artículo 86 de la Ley General de Títulos y Operaciones de Crédito cuando por imposibilidad del suscriptor pida o ruegue a un tercero que firme, debiendo hacer constar tal evento un fedatario público, notario o corredor, ya que de no observarse esta formalidad, el obligado al pago seria ese tercero, según lo determina el artículo 10 de la ley en consulta.

También queda obligado el suscriptor cuando alguien firma a su nombre, su apoderado, ya sea general o especial, los que ejercen la patria potestad, tutor y curador, pero en el primer supuesto, con autorización expresa para suscribir títulos de crédito según lo mandata el artículo $9^{\circ}$ último párrafo de la misma ley. En el

${ }^{18}$ Bejarano Sánchez, Manuel,“Obligaciones Civiles”, Sexta Edición, Oxford, pp. 4 ${ }^{19}$ Tena, Felipe de J. Ibid. 
caso especial de los representantes legales de incapaces que estén en la necesidad de suscribir pagares en su nombre, los que ejerzan la patria potestad o tutores, lo harán invariablemente mediante la autorización judicial correspondiente y así tenemos que, ante el evento de que el incapaz haya heredado una negociación mercantil, lo convierte en comerciante y los citados representantes, para el buen funcionamiento de la empresa, en ocasiones se hace necesario la firma de pagarés para garantizar "el cumplimiento" de la obligación derivado de la causa subyacente, contrato.

Si bien es cierto que la causa generadora de pagar una suma determinada de dinero es la firma, resulta también cierto que la causa general por la cual se estampa, ya sea por el propio suscriptor o un tercero a ruego, o bien, por su representante legal, es por que subyace generalmente un contrato.

El contrato es el acto jurídico por excelencia, causa general subyacente por la cual se firman títulos de crédito y así encontramos que en la compra venta de bienes y servicios, que son bilaterales por que generan derechos y obligaciones recíprocos, donde su pago se difiere (modalidad de la obligación a plazo, articulo 1953 del Código Civil Federal y su correlativo el 2131 del Código Civil Sonorense) y derivados de ellos, el vendedor o prestador de servicio le solicita al comprador la suscripción de uno o varios pagares a fin de "garantizar" la obligación derivada del negocio subyacente y éste, acepta firmarlos.

Al respecto, el autor Felipe de J. Tena, en desacuerdo con tratadistas que denominan a este acuerdo de voluntades para suscribir el pagaré, como la “convención ejecutiva," y que la consideran como la causa directa de la referida suscripción, manifiesta categóricamente que la citada convención ejecutiva en todo caso, debe ser considerada concausa, ya que fundamentalmente la causa 
de suscripción es el propio contrato, ya sea compraventa, apertura de crédito o mutuo. $^{20}$

Con plena convicción se sostiene, que si bien es cierto que el contrato es la causa general por la cual se suscribe el título de crédito, pagaré, también se sostiene que no es indispensable que subyazca este acto jurídico, ya que técnicamente, la obligación de pagar una suma determinada de dinero, su fuente es el diverso acto jurídico, declaración unilateral de voluntad, a que se refieren los artículos 1860 , 1861 y demás relativos del Código Civil Federal y sus correlativos 1991, 1992, 1993 del Código Civil para el Estado de Sonora, haciendo la pertinente aclaración de que esta concepción civilista determina que es revocable, pero en tratándose de relaciones cambiarias, la declaración unilateral contenida en el pagaré, la podríamos investir de cambiaria o bien, atípica, porque la promesa de pagar una suma determinada de dinero es de naturaleza irrevocable. ${ }^{21}$

La referida promesa no se hace exclusivamente al tomador beneficiario original, sino que es erga omnes, ya que la naturaleza del pagaré es circulatoria, por el único medio cambiario que es el endoso en propiedad, en el cual se dan los fenómenos de abstracción y autonomía, pudiendo ser trasmitidos también por otros medios legales como la cesión o la donación, pero en esta última hipótesis, sin los referidos fenómenos, operando en consecuencia la subrogación.

Al respecto L. Carlo Felipe Dávalos Mejía nos manifiesta: "La idea de considerar la obligación cambiaria una declaración unilateral de voluntad, en términos del Código Civil (artículos 1860 y ss.), ha sido superada con argumentos tan contundentes como: los títulos de crédito son formales y la declaratoria civil es consensual; los títulos son irrevocables, cuando entran en circulación, aun contra la voluntad del suscripto, en el supuesto de ser al portador (art. 70 de la Ley

20 Ibidem
${ }^{21}$ Dávalos Mejía, L. Carlos Felipe, ibid 
General de Títulos y Operaciones de Crédito), en tanto que la declaración civil es renunciable cuando se realiza por el mismo medio que la oferta..." Para este autor, si bien es cierto que acepta a la declaración unilateral de voluntad como fuente de obligación, también es muy cierto que debe ser de naturaleza atípica, pudiendo agregarse, de naturaleza cambiaria. ${ }^{22}$

En corroboración de lo anterior Felipe de J. Tena establece: “... No puede ponerse en duda tampoco que queda igualmente obligado aquel que firmó el título por broma o por hacer un modelo para fines didácticos o el que por error estampó en el su firma como deudor, creyendo firmar como testigo, o para dar un recibo. En todos estos casos el fundamento de la obligación es el mismo: la declaración de voluntad expresada en el título de crédito."

Al respecto Raúl Cervantes Ahumada señala: “...Consecuentemente, la ley mexicana es la fuente de la obligación consignada en un título de crédito, y la ley ha adoptado el sistema de la creación, para fundamentar en ella la obligación derivada de un título de crédito. Esto es: entre nosotros, quien crea un título crea una cosa mercantil mueble, que incorpora derechos, y la obligación deriva, en virtud de la ley, de la firma puesta en el titulo..."23

Efectivamente, el tenedor beneficiario original del pagaré, lo es por haberse expedido a su nombre, generalmente en garantía de pago por un bien o servicios prestados, bastando por parte del suscriptor una declaración unilateral de voluntad, cambiaria, atípica para quedar plenamente obligado y una vez firmado, debe hacer entrega material del mismo al acreedor, por lo que este último es propietario del papel y titular del derecho de crédito (personal) incorporado al mismo al tenor del artículo 38 de la Ley General de Títulos y Operaciones de Crédito y por lo tanto, forma parte activa de su patrimonio, teniendo el derecho real

\footnotetext{
${ }^{22}$ Ibidem

${ }^{23}$ Cervantes Ahumada, Ibid
} 
de propiedad del papel y el derecho personal, de crédito y consecuentemente, legitimado a disponer libremente de los mismos, ya que no tiene restricción legal alguna.

En este orden de ideas, podemos concluir que si bien es cierto que el contrato es la fuente general subyacente por la cual se suscribe un pagaré, resulta también cierto que basta la declaración unilateral de voluntad, cambiaria, atípica para que surja a la vida jurídica y por su naturaleza circulatoria, pueden concurrir las firmas autógrafas del suscriptor, avalista y endosantes en propiedad, surgiendo entre ellos la relación jurídica sustantiva y de la cual deriva la obligación de pagar el valor literal del título de crédito, constituyendo un litisconsorcio pasivo, por lo que resulta de vital importancia analizar la naturaleza o modalidad de sus obligaciones, sosteniendo que en las mismas no se dan los beneficios de orden, excusión y división que prevalecen en la fianza civil (Artículos 3134, 3135 y 3336 del Código Civil para el Estado de Sonora), los cuales consisten:

- Orden.- Implica que el acreedor, en primer lugar debe exigir el pago al deudor principal o fiado y posteriormente al fiador.

-Excusión.- significa que en primer lugar, se deben embargar bienes propiedad del deudor principal o fiado y en el supuesto de que éste no tenga o sean insuficientes el embargo será en bienes del fiador.

Los dos beneficios antes mencionados operan por ministerio de ley, pero por ser derechos subjetivos privados, son renunciables en forma expresa y por escrito,

- División.- Consiste en dividir la deuda entre tantos fiadores existan y para que opere es necesario convenirlo expresamente.

También se hace de imperiosa necesidad recurrir al Título Segundo, Capitulo Primero del Código Civil para el Estado de Sonora y que reglamenta las 
modalidades de las obligaciones condicionales, a plazo, conjuntivas, alternativas, mancomunadas y solidarias.

- Condicionales. La existencia, su resolución o extinción dependen de un acontecimiento futuro e incierto. (Artículo 2115)

- A plazo. Implica la inexigibilidad del pago toda vez que para su cumplimiento se ha señalado un día cierto. (Artículo 2130).

- Conjuntivas. Cuando la persona se ha obligado a realizar cosas o hechos en forma conjunta por lo que para su cumplimiento debe dar todas las cosa a que se halla obligado y también debe prestar todos los hechos convenidos.(Articulo 2138).

- Alternativas. Cuando la persona se obliga a dos o más hechos, o a dos o más cosas o bien a un hecho o a una cosa cumple realizando cualquiera de esos hechos o dando cualquiera de las cosas. (Artículo 2139).

- Mancomunidad. Se trata de una obligación compleja puesto que se da cuando existen dos o más deudores o dos o más acreedores respecto de una misma obligación e implica, que cada uno de los deudores no está obligado a cumplir íntegramente la obligación y por parte de los acreedores no pueden exigir cada uno la totalidad del cumplimiento ya que tanto la obligación como el derecho por ley se dividen entre tantos deudores y acreedores haya, por lo que cada parte constituye una deuda o bien un crédito distinto uno de otro. $Y$ existe presunción legal que las partes son iguales. (Artículo 2161, 2162 y 2163).

- Solidaridad. También se trata de una obligación compleja puesto que se da cuando existen dos o más deudores quienes reportan la obligación de pagar totalmente, y dos o más acreedores y cada uno de por si tiene el derecho de 
exigir el cumplimiento total de la obligación en el entendido de que la solidaridad resulta de la ley o de la voluntad de las partes, es decir, no se presume. (2164 y 2165).

Si la solidaridad no se presume ya que ésta nace de la voluntad de las partes o de la ley, tenemos que las firmas del suscriptor, avalista, endosantes en propiedad y avalistas de estos últimos, sin lugar a dudas se ubican en la modalidad de solidaridad legal, no convenida, y así lo determina la Ley General de Títulos y Operaciones de Crédito:

Artículo 154.- El aceptante, el girador, los endosantes y los avalistas responden solidariamente por las prestaciones a que se refieren los dos artículos anteriores. El último tenedor de la letra puede ejercitar la acción cambiaria contra todos los obligados a la vez, o contra alguno o algunos de ellos, sin perder en ese caso la acción contra los otros, y sin obligación de seguir el orden que guardan sus firmas en la letra. El mismo derecho tendrá todo obligado que haya pagado la letra, en contra de los signatarios anteriores, y del aceptante y sus avalistas.

De la interpretación armónica del numeral antes transcrito, podemos concluir definitivamente que en las obligaciones cambiarias se encuentran ausentes los principios de orden, excusión y división, ausentes las modalidades de la mancomunidad, la condición, las conjuntivas o alternativas y únicamente campea la obligación solidaria y generalmente a plazo, resultando de especialísima naturaleza la obligación cambiaria surgida, en todo caso de la declaración unilateral de voluntad atípica, entiéndase irrevocable, con el fin primordial de preservar el título de crédito, fomentar su circulación generando riqueza y sobre todo, facilitar su pago al acreedor cambiario de buena fe, legitimado a reclamarlo a cualquiera de los signatarios, sin seguir un orden y a embargarlos indistintamente, por el monto total del valor literal del pagaré. 
Excepcionalmente, en las relaciones cambiarias, en un sólo caso se da la obligación mancomunada y es el contemplado en el artículo 159 de la Ley General de Títulos y Operaciones de Crédito, cuando dos o más personas suscriben un mismo acto, por ejemplo, cuando firman cuatro personas como avalistas del suscriptor, entre ellos y solamente entre ellos internamente son codeudores, es decir, obligados mancomunados, pero solidarios externamente.

Ahora bien, todas las firmas puestas o estampadas en el pagaré no generan idéntica consecuencia, la del suscriptor, la obligación cierta y directa de pagar una suma determinada de dinero; la del avalista, garantiza el pago total o parcial del pagaré y la de los endosantes en propiedad, la responsabilidad u obligación indirecta de pagar el valor literal del título de crédito y consecuentemente, el pago que haga el suscriptor es el único que extingue la obligación que previamente incorporó y el realizado por persona diferente al obligado, el avalista por ejemplo, en virtud de que éste no incorporó la obligación, únicamente la garantiza, tiene acción contra su avalado para recuperar lo que haya pagado menos las costas y por último, si el pago lo hace cualquiera de los endosantes en propiedad, también pueden recuperar lo pagado en acción cambiaria de regreso contra los endosantes anteriores e incuestionablemente, en la vía directa contra el suscriptor del pagare y su avalista(s) artículos 115, 150 al 154 de la Ley General de Títulos y Operaciones de Crédito, por la subrogación que por ley opera.

\section{IV.-Síntesis o Conclusión}

Sin lugar a dudas que los fenómenos cambiarios referidos de abstracción y autonomía que se manifiestan en cabal plenitud únicamente al trasmitirse el pagaré, pero no por cualquier medio legal como sería la cesión o la donación, sino por el único medio cambiario que es precisamente el endoso en propiedad, acto jurídico causa de estos fenómenos, los cuales trastocan concepciones civilistas en sentido estricto. Efectivamente, la legislación civil al reglamentar el acto jurídico 
por excelencia, el contrato, para que sea plenamente válido, debe observar, entre otros requisitos, la usencia de vicios en la voluntad, ya que si ésta fue dada por error, violencia o dolo, acarrearía su invalidez afectándolo de nulidad relativa y si se omite un elemento esencial, lo sanciona con la inexistencia jurídica.

Ahora bien, tratándose de obligaciones y derechos cambiarios nacidos precisamente en el pedazo de papel al cual se le incorporaron todos los requisitos exigidos en el artículo 170 Ley General de Títulos y Operaciones de Crédito, es decir, cumplida su formalidad, el título de crédito, pagaré producirá plenamente todos sus efecto y como esencialmente nace para circular, cuando su tenedor beneficiario lo endosa en propiedad, el negocio subyacente causa de su emisión, generalmente un contrato, aun en el supuesto de que éste estuviera afectado de inexistencia o bien, de nulidad, ya no afectaría al título de crédito, haciéndose inmune el nuevo derecho del endosatario en propiedad a cualquiera de estas circunstancias de las cuales resulta ajeno, lo que implica que al ejercer su derecho de cobro no le podrán interponer excepcione derivadas del referido contrato subyacente que dio origen a la emisión del pagaré endosado, por los fenómenos cambiarios de abstracción y autonomía, siempre y cuando el endosatario en propiedad sea de buena fe y ésta, es presumida por la ley.

En este orden de ideas, tenemos que el artículo 34 de la Ley General de Títulos y Operaciones de Crédito contraviene el referido criterio jurisprudencial al determinar que el endoso en propiedad transfiere la propiedad del título de crédito, pagaré y de todos los derechos a él inherentes, entre otros, el de cobro ya que de ser así, operaria una subrogación legal (artículo 27) que trasmitiría todos los derechos, entre ellos, el de cobro, pero también trasmitiría las obligaciones al adquiriente-subrrogatario y por ende, sujetándolo a todas las excepciones personales que el suscriptor tenga contra el propio tenedor beneficiario originalcedente. 
Continuando con el análisis del artículo 34 y tomando en cuenta que el título de crédito, pagaré, está constituido de un pedazo de papel al cual se le incorpora el derecho de cobro, podría manifestarse que el endosante si trasmite la propiedad del papel mas no el derecho personal, de cobro, el cual es conceptuado como un nuevo derecho, nacido precisamente del endoso en propiedad y desligado del derecho de sus antecesores y por lo tanto, inmune a las excepciones personales.

Este mismo numeral pretende crear una regla general en el sentido de que el endosante en propiedad no quede obligado solidariamente y que por excepción sí. Tal pretendida regla general del no, se convierte en excepción y el sí en regla general. Efectivamente, todo el que endosa en propiedad un título de crédito sí queda obligado solidariamente, como sería el caso del endosante de la letra de cambio, pagare, cheque, obligaciones, certificado de depósito y bono de prenda y por excepción, no quedaría obligado el que endosa una acción o bien un certificado de depósito. (Artículos 90, 174, 196, 228, 251 segundo párrafo).

En los casos de que la ley establezca la solidaridad, se puede liberar de ella insertando la literalidad "sin mi responsabilidad" u otra equivalente. Literalidad extraordinaria que sólo produce efecto cuando se inserta en el endoso en propiedad.

Consecuencia igual a la del referido artículo 34, establece en su primera parte el diverso numeral 18 al determinar: "La transmisión del título de crédito implica el traspaso del derecho principal en él consignado $y, . . . "$

La parte antes transcrita, su concepto transmisión, es de naturaleza genérica y por lo tanto, en él queda incluida la especie, endoso en propiedad, contenido en el citado artículo 34 . El numeral 18 en comento, también contraviene la doctrina y el criterio jurisprudencial con antelación transcrito, toda vez que la referida transmisión del derecho principal también implicaría subrogación. 
Ambas disposiciones legales, en la parte que son motivo de comentario, contravienen la naturaleza especialísima del derecho de cobro ya que al darse la subrogación, la causa subyacente, original por la cual se suscribió el pagaré, seguiría siendo relevante e influyente y en un momento dado, nulificaría el derecho del ultimo endosatario en propiedad que nada tuvo que ver con la misma. En este orden de ideas, proponemos reformar estos dos artículos y cualquier otro relacionado, para hacerlos acordes a la naturaleza especial del derecho y de la obligación cambiarios.

Estos principios de abstracción y autonomía de las obligaciones y derechos, van encaminados directamente a preservar al propio título de crédito, su circulación y su pago, protegiendo a los endosatarios en propiedad de buena fe.

Aunado a lo anterior y atenta a la especial naturaleza de la obligación incorporada en el pagaré, en el supuesto de que en éste aparecieran firmas falsas, imaginarias o de incapaces, todas las firmas reales, auténticas y de capaces si producirían plenamente sus efectos, aun en el supuesto de alteración ya que en esta hipótesis, ningún signatario puede llamarse extraño a la relación cambiaria y todos quedan obligados, unos de acuerdo al texto alterado y otros conforme al texto antes de la alteración y en caso de duda conforme al texto original, por la autonomía de la obligaciones y los derechos cambiarios, (artículos 12 y 13 ) $^{24}$ fenómeno que no acontecería en las relaciones sustantivas de estricto derecho civil.

${ }^{24}$ Ley General de Títulos y Operaciones de Crédito, en vigor a partir del día 15 de Septiembre de 1932 


\section{Bibliografía y Webgrafia}

Bejarano Sánchez, Manuel,“Obligaciones Civiles”, Sexta Edición, Oxford,México

Cervantes Ahumada, Raúl,Títulos y Operaciones de Crédito,Ed. Porrúa,México,

Dávalos Mejía, L. Carlos Felipe,Títulos y Operaciones de Crédito, Tercera Edición, Ed. OXFORD.México

Segunda Edición; Ed. Harla,México,

Títulos y Contratos de Crédito, Quiebras,

Tena, Felipe de J., Derecho Mercantil Mexicano, Vigesimosegunda Edición, Ed. Porrua

Vivante, Cesar. http://es.slideshare.net/videoconferencias/de-los-ttulos-valor15685870

\section{Legislación}

Código Civil para el Estado de Sonora, vigente a partir del 8 de julio de 1949.

Ley General de Títulos y Operaciones de Crédito, en vigor a partir del día 15 de Septiembre de 1932 